\title{
Editorial for European Transport Research Review Vol 6 Issue 1
}

\author{
Anthony D. May
}

Published online: 7 January 2014

(C) The Author(s) 2014. This article is published with open access at SpringerLink.com

This issue marks 5 years since the European Transport Research Review was launched by the European Conference of Transport Research Institutes, ECTRI, as an open access journal published by Springer-Verlag.

The main goal of the journal remains that of providing a forum for the publication of high quality scientific papers in the field of transport in general, and a dissemination medium for new ideas and developments that originate in, or are of interest to, the European transport research community. The six principal themes covered by the journal are transport economics, planning and policy; transport systems management and technology; mobility and behaviour; transport and the environment; safety, security and human factors; and freight and logistics.

The eight articles in this issue illustrate the journal's breadth of coverage, both of subject matter and of disciplinary input. While five of the articles consider aspects of safety, they do so from the standpoints of sociology, psychology, anthropology and epidemiology, and address the safety of truck drivers, motorcyclists and bus passengers as well as the general travelling public. Of the other three, one deals with the optimisation of aircraft movements to reduce airport noise, one with the effects of reliability of real time information on route choice, and the third with the causes of travel time uncertainty on motorways. While seven of the eight are from European universities and research institutes, the last mentioned is a welcome contribution from Japanese colleagues on a topic of international interest.

This issue also marks a change in the management of the journal. Dr Evangelos Bekiaris has stepped down from the

\section{A. D. May}

10 Newton Terrace, York YO1 6HE, England, UK

\section{A. D. May $(\bowtie)$}

Emeritus Professor of Transport Engineering, The University of Leeds, Leeds, England, UK

e-mail: a.d.may@its.leeds.ac.uk position of editor-in-chief after leading the journal throughout its inaugural 5 year period. I am greatly honoured to have been invited by the Advisory Board to succeed him, and am delighted to have the opportunity to work with a team of new and continuing associate editors, who are listed on the front cover of this issue.

We also have the agreement of Springer to increase our output to 30 articles per year. This is particularly timely, given the imminent completion of research under the European Commission's seventh framework programme and the current launch of the eighth programme as Horizon 2020. While the Commission's programmes have been wide ranging and intensive, their output has not always been effectively disseminated. The journal's editorial team are keen to help remedy this, and have been in discussion with the Commission on ways of facilitating its requirements for open access publication of the outputs of Horizon 2020. In the meantime we welcome contributions which highlight the scientific contributions from seventh programme projects, and are willing to consider publishing sets of articles which encompass the output of the larger integrated projects. We would be interested to receive proposals for special issues to cover larger projects or themes.

I would like to take this opportunity to thank Dr Bekiaris and his editorial team for their leadership of the journal over its critical inaugural 5 year term, and Cristina Pronello, the outgoing chair of the journal's Advisory Committee. I look forward to working with the journal's authors, reviewers and editors, and welcome any suggestions of ways in which we can further expand the journal's coverage and readership, further enhance the quality of the articles which we publish, and hence more fully meet the objectives which we have set for the journal.

Open Access This article is distributed under the terms of the Creative Commons Attribution License which permits any use, distribution, and reproduction in any medium, provided the original author(s) and the source are credited. 